\title{
Body fat: our own Janus
}

Despite its negative reputation, body fat or adipose tissue is - in the right proportion and quantity - fundamental to many physiological functions. Too much body fat, however, is strongly associated with diseases such as Type II diabetes, cardiovascular diseases and some forms of cancer. Body fat is more than just a passive tissue and an improved understanding of its properties will enable us to better target obesity.

\section{E Louise Thomas E. Fimmy Bell}

Metabolic and Molecular Imaging Group, MRC Clinical Sciences Centre, London, UK

'a media driven vision of the 'ideal body' having little or no body-fat, is distorting the true place of adipose tissue in human physiology and its importance to human health'

With the discovery of leptin, adipose tissue (commonly referred to as 'body-fat') was transformed from a humble tissue to a complex and intricate organ. Today we know that adipose tissue interacts with virtually every organ in the body to ensure optimal homeostasis. Yet, most people continue to view adipose tissue in a negative light, ignoring its pivotal role in maintaining our health. But the story of adipose tissue is not as straightforward as we initially thought; it turns out that it is not only about how much fat we carry but also about its composition and distribution.

Obesity is endemic in many parts of the world, with little signs of abating. If obesity continues to increase at the current rate, it is estimated that well over 1 billion people in the world will be overweight or obese by 2050. This, together with a media driven vision of the 'ideal body' having little or no body-fat, is distorting the true place of adipose tissue in human physiology and its importance to human health. This negative view is best exemplified by a survey of young girls whose number one 'magic wish' was be thin (Kilbourne, 1994). Clearly, a re-

balancing of our attitude to fat is urgently required. It is essential that we have a better understanding of the different functions of adipose tissue and how content and distribution can affect our health. It is essential to dispel the current dogma that all body-fat is bad and undesirable; at the same time we need to become more aware of the physiological cost of carrying too much body-fat and the health implications of depositing it in the 'wrong' places.

The anatomy of adipose tissue

Adipose tissue (AT) is a beautiful and complex organ fundamental for the optimal functioning of our bodies, affecting virtually all organs and cell types, mainly through the production of chemical signals known as adipokines. Adipose tissue is associated with many fundamental physiological functions, including fertility and immune responses, affording us protection from the environment, as well as modulation of our moods and appetite. Adipose tissue can be found in almost every part of our anatomy making it the largest organ in our body, from the large subcutaneous depots covering our bodies (especially around the waist and hips), to distinct depots behind our eyes, around our heart and behind the knees (Fig. 1).

In the general adult population, levels of adipose tissue ranges from 3.5 to $98.0 \mathrm{~kg}$, corresponding to a percentage body-fat of 4.0-68.0\%. So what is the right amount of AT for an adult? At present we do not have exact values for this, but, in terms of a healthy percentage body-fat, it is recommended that women aim for 21-24\%, while men should aim for 14-17\% (Jeukendrup \& Gleeson, 2010). Similarly, it is suggested that the percentage body-fat for women should not go below $10-13 \%$ or 2-5\% for men, referred to as essential fat percentage; extremely low levels of AT are known to be associated with metabolic 
contraindications, as well as affecting fertility and immune responses to injury and infection. Moreover, let us not forget that individuals with lipodystrophy (a genetic condition where AT levels are extremely low or virtually absent) suffer from many of the metabolic conditions observed in obesity (Capeau et al., 2010).

At a cellular level adipose tissue can be broadly defined as being composed of adipocytes, endothelial and nerve cells (innervation), as well as inflammatory cells including macrophages, neutrophils and lymphocytes. Adipocytes, which are the principal component of adipose tissue, can in turn be subdivided into 'white' (responsible lipid storage and production of most adipokines), 'brown' (associated with thermogenesis - its presence in adults only recently being confirmed) and 'beige' (a sort of half-way house between the first two, but with quite distinct properties)

(Park et al., 2014).

Indeed the concept of 'beige fat' has recently attracted much attention given its potential as an anti-obesity mechanism. It turns out that a number of physiological events, including exercise, as well as some natural and pharmacological compounds can increase the thermogenic properties of subcutaneous adipose tissue through a process that has come to be known as 'browning' (Bartelt \& Heeren, 2014). It is currently unclear if the process of browning takes place by increasing expression of thermogenic-UCP1 in white adipocyte or by the recruitment of dormant 'beige adipocytes'. Regardless, the overall effect is an increase in whole-body energy expenditure and a reduction in weight and adipose tissue, along with an improvement in glucose homeostasis.

Levels of other cells are highly dependent on the 'health' status of the individual, with for example inflammatory cells increasing significantly in number with obesity, making up to $50 \%$ of cells in some adipose tissue depots. These cells are crucial in the chronic and low-grade state of inflammation normally associated with increased adiposity, especially abdominally obesity.

\section{Adipose tissue content and} distribution: implications for health and well-being

It is now generally accepted that increased body adiposity can lead to a plethora of metabolic complications including the metabolic syndrome, insulin resistance, type Il diabetes, cardiovascular disease and some forms of cancer. At population level the relative risk of developing these disorders appears to increase linearly with increases in AT content. Although most of these studies were based on the use of body mass index (BMI) as a measure of adiposity, the advent of non-invasive imaging techniques, especially magnetic resonance imaging (MRI), have confirmed some of these findings. Moreover, the capability to directly determine total and regional content has shown that adipose tissue distribution is also important.

We now know for example that 'abdominal obesity' (adipose tissue around the abdomen, both subcutaneous and intra-abdominal also known as 'visceral fat') does not carry the same risk as 'peripheral adiposity' (adipose tissue around hips and thighs). If anything, the latter is seen as benign and even cardioprotective, especially glutealfemoral adipose tissue. On the other hand deposition of visceral adipose tissue is strongly associated with the metabolic syndrome, insulin resistance and type II diabetes. So it is not only the quantity but also the distribution of adipose tissue that determines the relative risk observed with increased adiposity.

\section{Ectopic fat}

Beside fat accumulation in adipose tissue, lipids in the form of triglycerides can also be deposited in the liver (intra-hepatocellular lipid, IHCL), muscle (intramyocellular lipid $I M C L$ ), pancreas (intra-pancreatic cellular lipid, IPCL) and heart. These fat depots are part of what is known as 'ectopic fat', some of which appear to be independent risk factors for the development of type II diabetes (Fig. 2) (Thomas \& Bell, 2006). Indeed, an extensive number of published studies have shown that $\mathrm{HCL}$ is an independent risk factor for insulin resistance, while IPCL appears to play an important role in the process of pancreatic dysfunction through 'lipotoxicity'. Elevation of ectopic fat in liver and pancreas is closely associated with central obesity and although the exact mechanism is not fully understood, it may in part arise from the inability of adipose tissue in some individuals to efficiently sequestrate circulating plasma triglycerides and free fatty acids.

Today, like obesity, the number of individuals presenting elevated $\mathrm{IHCL}$ is reaching epidemic proportions, with reports from the UK and USA putting the number of cases in the general population to over $45 \%$ (Szczepaniak et al., 2005). The concern over elevated IHCL goes beyond its direct effect on insulin sensitivity, since we know that fatty-liver can eventually progress into liver fibrosis and liver cancer (hepatocellular carcinomas - HCCs) (Powell et al., 1990).

\section{Adipose tissue distribution: $\mathrm{MHO}$, MONW and TOFIs}

Over a decade ago Prentice and Jebb wrote a seminal review entitled 'Beyond body mass index', in which they summarised some of the

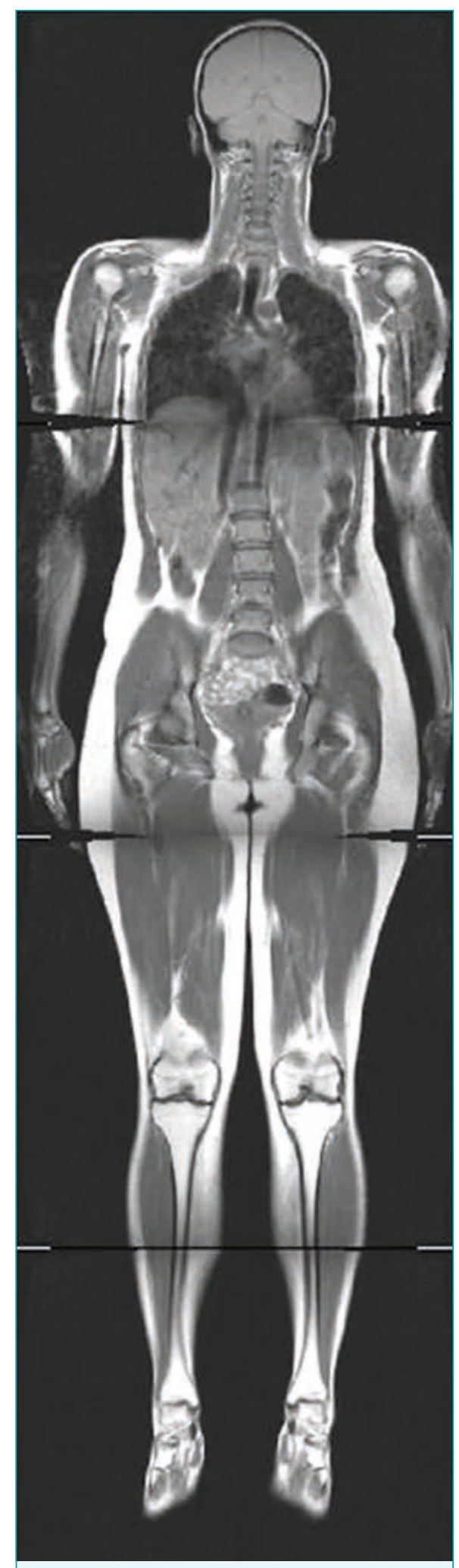

Figure 1. Coronal MR image from a healthy female volunteer, adipose tissue (and bone marrow) appears as bright white in this image and can be seen both covering the outside of the body (subcutaneous adipose tissue) as well as within the body (internal adipose tissue) 


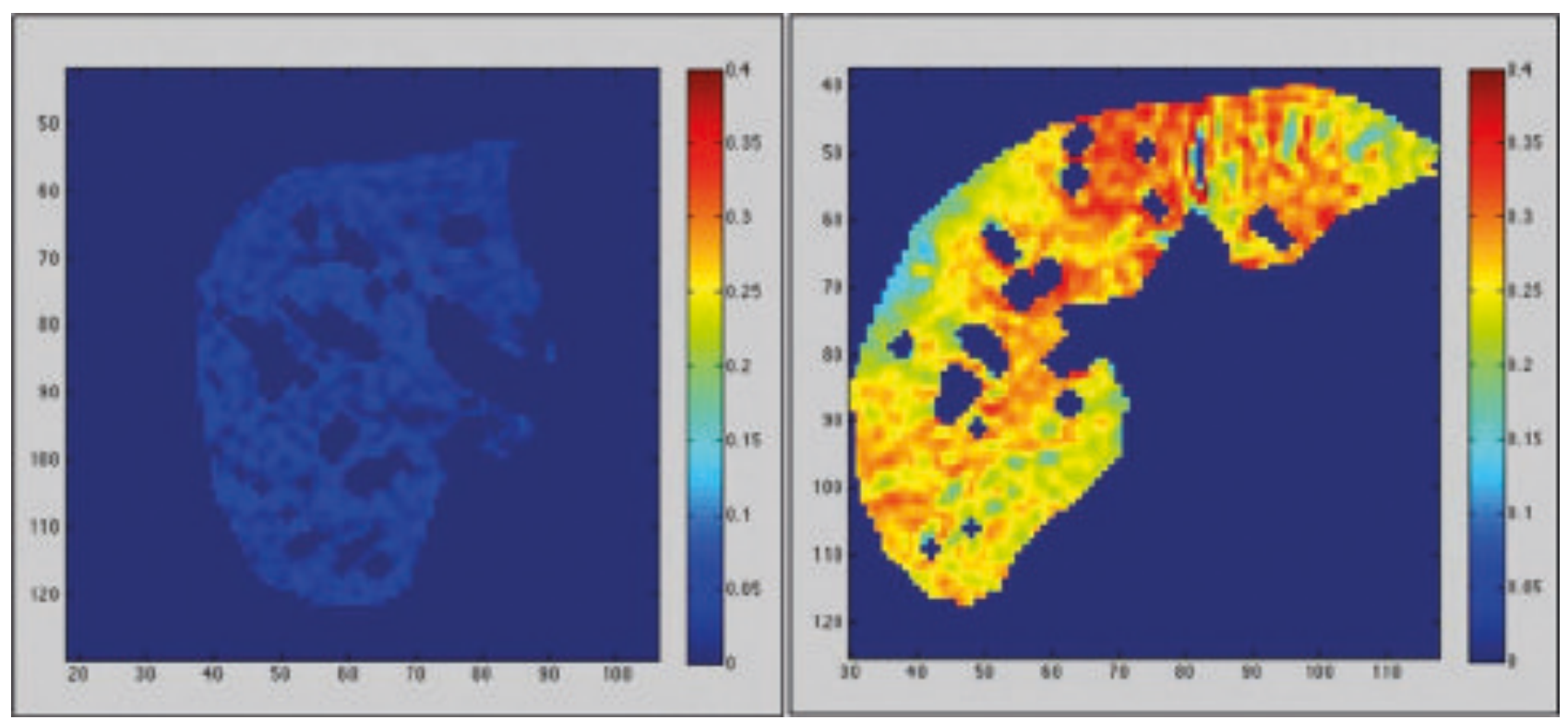

Figure 2. ME heat map from subjects with low IHCL (2.9\%) and high IHCL (26.1\%) content. Increasing IHCL content is shown by the colour map changing from blue (low) to red (high).
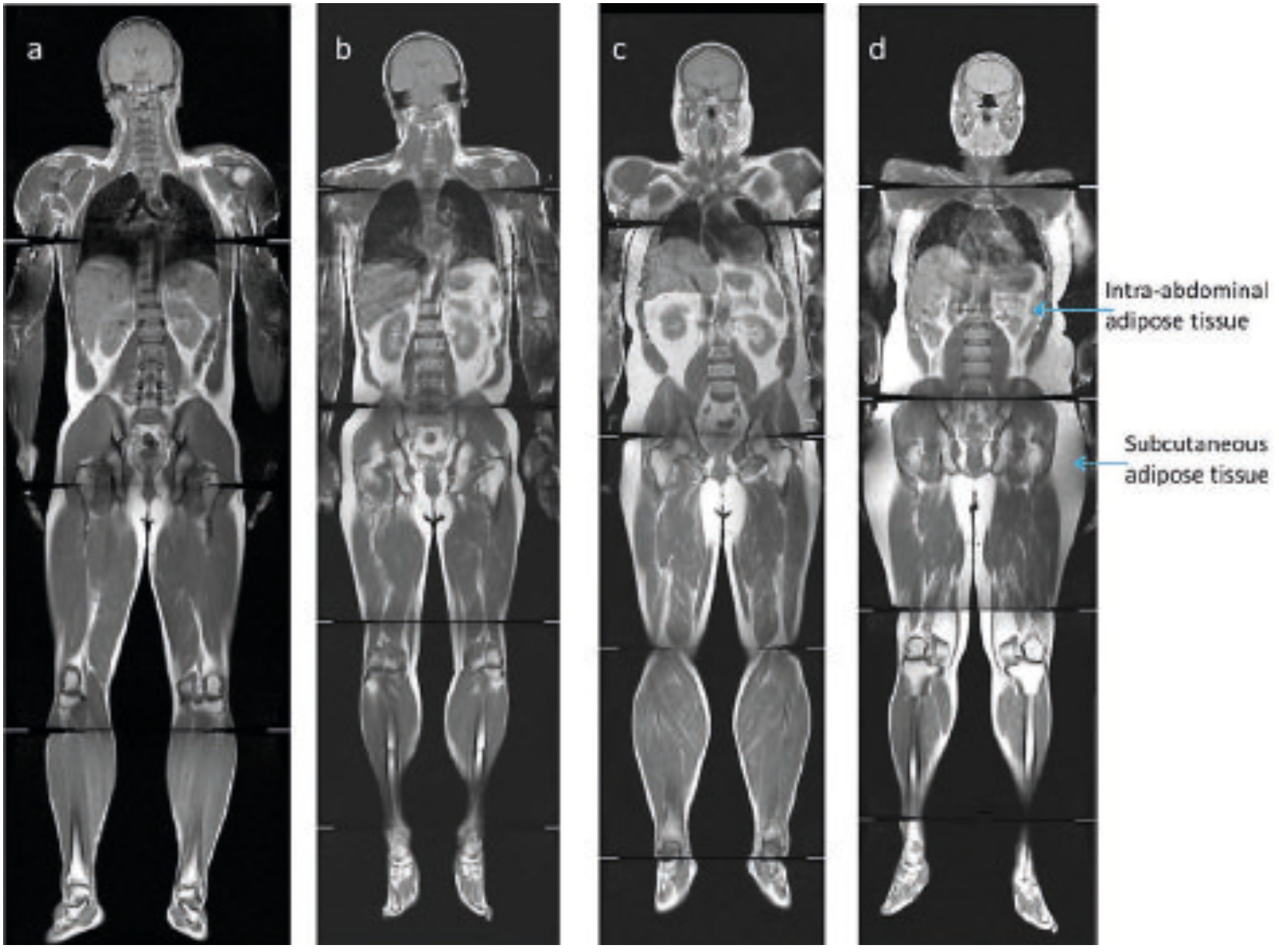

Figure 3. Coronal MRI images from four male subjects, classified from their adipose tissue distribution as (a) lean control BMI $25.5 \mathrm{~kg} / \mathrm{m}^{2}$, IAAT = 1.0 litres; (b) TOFI BMI $25.8 \mathrm{~kg} / \mathrm{m}^{2}$, IAAT = 4.6 litres; (c) obese control BMI $36.9 \mathrm{~kg} / \mathrm{m}^{2}$, IAAT = 5.6 litres; (d) MHO BMI $36.4 \mathrm{~kg} / \mathrm{m}^{2}$, IAAT $=0.9$ litres 
shortcomings of what was seen at the time as the main tool for assessing body adiposity, principally BMI (Prentice \& Jebb, 2001). Central to their argument, and those of others, was that the BMI of a subject said little about the actual body composition of that individual, even less about the distribution of adipose tissue. Put simply, a body-builder and a morbidly obese person would be categorised as having the same $\mathrm{BMI}$, despite the fact that the levels of skeletal muscle and adipose tissue are completely different. Indeed, just recently the story of a sportswoman who was told by an NHS nurse to go on a strict diet purely based on her high BMI hit the headlines (Metro, 2014). This is an all too common happening for many athletes with a high degree of musculature.

Similarly, subjects with a similar BMI and overall level of adiposity, but a totally different adipose tissue distribution are usually assumed to have the same risk of disease. However, as we now well know, differences in adipose tissue distribution convey a very different risk of metabolic disease. Differences in adipose tissue distribution arising from sex are a good example of this, where men present more abdominal adiposity than women and consequently carry a higher risk of metabolic disease. Similarly when women go through the menopause, despite minor changes in body weight, significant changes in adipose tissue distribution are observed, reflecting increasing risk of metabolic disease.

Since then, and with the introduction of MRI and CT in clinical studies, the importance of accurately determining adipose tissue distribution has become abundantly clear. Subjects matched for BMI and waist-to-hip ratio can have significantly different levels of visceral adipose tissue and ectopic fat (Thomas et al., 2012). These differences were crucial in unravelling the metabolic and physiological differences observed between subjects with identical anthropometric parameters. In turn this led to the identification of a number of subphenotypes, including the 'metabolically healthy obese' (MHO), the 'metabolically obese but normal-weight' (MONW) and the 'TOFI' (thin-outside-fat-inside) individuals (Fig. 3). Each of these sub-phenotypes represents significant variations in adipose tissue distribution and relative risk of developing insulin resistance or type- 2 diabetes. Thus, it is no longer possible to define subjects simply based on $\mathrm{BMI}$ or other anthropometric dimensions; accurate assessment of adipose tissue distribution has become essential for human studies of obesity and associated risk factors.

Metabolically healthy obese ( $\mathrm{MHO}$ or 'fat-fit') subjects have been reported by a number of groups and refer to individuals with increased BMI (and in some cases waist-hip ratio), carrying considerable levels of adipose tissue while still maintaining normal insulin sensitivity, blood pressure, high HDL and low levels of plasma triglycerides (Wildman et al., 2008). The best example of this subphenotype is of course Sumo wrestlers, many of whom have BMI well above $40 \mathrm{~kg} / \mathrm{m}^{2}$. There are those of course that dispute the existence of true $\mathrm{MHO}$ subjects, as they consider any form of obesity as being 'unhealthy', pointing out that all MHO individuals do present with some metabolic abnormalities, especially those associated with inflammatory markers.

Another important subphenotype, the 'metabolically obese but normal-weight (MONW), comprises lean subjects (BMI <25 $\mathrm{kg} / \mathrm{m}^{2}$ ) with metabolic profiles normally observed in the obese, including reduced insulin sensitivity, reduced HDL and raised blood pressure (Ruderman et al., 1981). With the advent of MRI this subphenotype has been further refined, known as 'TOFI' (thin-outside-fat-inside), showing that central to its dysfunctional metabolic profile is a disproportionate deposition of visceral adipose tissue (Fig. 3), in some cases accompanied by elevated IHCL (Thomas et al., 2012). This subphenotype can be found in a significant proportion of the lean population (>10\%), especially amongst those that aim to maintain a 'normal weight' through diet-based lifestyle choices, with little or no physical activity.

\section{Life-style choices for a healthy adipose tissue}

The importance of adipose tissue to our health cannot be over-stated. Adipose tissue should not be seen as the passive tissue whose sole purpose was to store excess energy in the form of fat. Adipose tissue is a complex organ with a crucial role in maintaining whole body homeostasis. Moreover, it is no longer about how much adipose tissue we carry, but also its distribution. The lifestyle choices we make will impact on adipose tissue distribution as well as content, so we need to ensure that both a healthy diet and a significant amount of physical activity are part of everyday life. We need to focus more on fitness rather than thinness. Be nice to your adipose tissue and your adipose tissue will be nice to you.

\section{References}

Bartelt A \& Heeren J (2014). Adipose tissue browning and metabolic health. Nat Rev Endocrinol 10, 24-36.

Capeau J, Magré J, Caron-Debarle, Lagathu C Antoine B, Béréziat V, Lascols O, Bastard JP \& Vigouroux C (2010). Human lipodystrophies: genetic and acquired diseases of adipose tissue. Endocr Dev 19, 1-20.

Jeukendrup A \& Gleeson M (2010). An Introduction to Energy Production and Performance Sport Nutrition, 2nd Edition. Human Kinetics Publishers, Leeds, UK.

Kilbourne J (1994). Still killing us softly: Advertising and the obsession with thinness. Feminist Perspectives on Eating Disorders. pp. 395-419. The Guilford Press, New York.

The Metro Newspaper (2014). A picture of obesity NHS tells bodybuilder she must lose weight and exercise more. 26 March.

Park A, Kim WK \& Bae KH (2014). Distinction of white, beige and brown adipocytes derived from mesenchymal stem cells. World J Stem Cells 6, 33-42.

Powell EE, Cooksley WG, Hanson R, Searle J, Halliday JW \& Powell LW (1990). The natural history of nonalcoholic steatohepatitis: a follow-up study of forty-two patients for up to 21 years. Hepatology 11, 74-80.

Ruderman NB, Schneider SH \& Berchtold P (1981) The 'metabolically-obese,' normal-weight individual. Am J Clin Nutr 34, 1617-1621.

Szczepaniak LS, Nurenberg P, Leonard D, Browning JD, Reingold JS, Grundy S, Hobbs HH \& Dobbins RL (2005). Magnetic resonance spectroscopy to measure hepatic triglyceride content: prevalence of hepatic steatosis in the general population. Am J Physiol Endocrinol Metab 288, E462-468.

Thomas EL \& Bell JD (2006). Intra-cellular fat accumulation, mechanisms and implications for health. Int J Body Comp Res 4, 27-37.

Thomas EL, Parkinson JR, Frost GS, Goldstone AP, Doré CJ, McCarthy JP, Collins AL, Fitzpatrick JA, Durighel G, Taylor-Robinson SD \& Bell JD (2012). The missing risk: MRI and MRS phenotyping of abdominal adiposity and ectopic fat. Obesity 20, 76-87.

Wildman RP, Muntner P, Reynolds K, McGinn AP Rajpathak S, Wylie-Rosett J \& Sowers MR (2008). The obese without cardiometabolic risk factor clustering and the normal weight with cardiometabolic risk factor clustering: prevalence and correlates of 2 phenotypes among the US population (NHANES 1999-2004).

Arch Intern Med 168, 1617-1624 